\title{
Kinetic modeling of a heterogeneous Fenton-type oxidative treatment of complex industrial effluent
}

\author{
Laura Covinich $^{1} \cdot$ Fernando Felissia $^{1} \cdot$ Paola Massa ${ }^{2} \cdot$ Rosa Fenoglio $^{2} \cdot$ María C. Area $^{1}$
}

Received: 12 October 2017 / Accepted: 6 September 2018 / Published online: 17 September 2018

(c) The Author(s) 2018

\begin{abstract}
This work proposes a kinetic model for the reactions involved in the heterogeneous copper-based Fenton-type oxidation of mixed recalcitrant compounds in a real industrial effluent from the alkaline sulfite treatment of wood. This kind of treatment is unusual in this industry due to the complexity of the effluents and the high costs involved in total mineralization of the organic matter. Nevertheless, conversion of recalcitrant to degradable compounds and catalyst recovery can make the difference. The complexity of the effluent and the great number of compounds formed as intermediates, make extremely difficult the identification and quantification of the individual reactions that occur during oxidation. To solve this drawback TOC parameter was used as a representative measurement. To verify the level of TOC degradation produced by the heterogeneous catalysis reaction, experiences of homogeneous catalysis and adsorption were accomplished. The studied temperature range was $45-80^{\circ} \mathrm{C}$. A "two-step" kinetic model was applied to TOC reduction in heterogeneous and homogeneous oxidations, admitting two sequential steps of oxidation: a first fast stage ("seconds stage") followed by a slow one ("minutes stages"). Kinetic constants were obtained for both processes and activation energies were also determined for the "minutes stage" step $(33.17 \mathrm{~kJ} / \mathrm{mol}$ and $15.13 \mathrm{~kJ} / \mathrm{mol}$, respectively). Homogeneous catalysis studies confirm mass transfer limitations in heterogeneous oxidations. Experiences of adsorption of organic matter on $\mathrm{CuO} / \gamma-\mathrm{Al}_{2} \mathrm{O}_{3}$ catalyst demonstrated that this phenomenon is exothermic and cannot be neglected. The activation energy of adsorption was determined as $7.32 \mathrm{~kJ} / \mathrm{mol}$. Catalysts were characterized through SEM, EDS, XRD, FTIR, and TGA.
\end{abstract}

\section{Graphical Abstract}

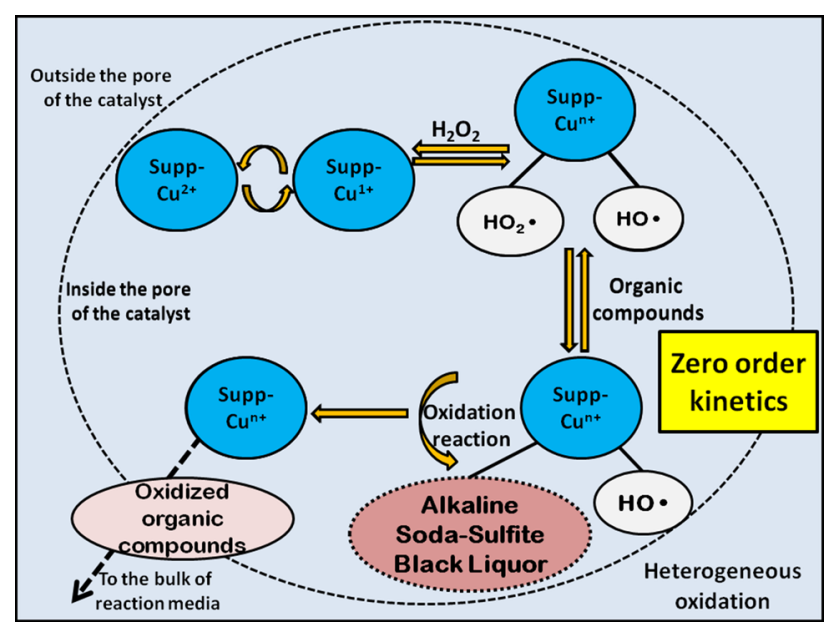

Keywords Advanced oxidation · Alkaline sulfite wood treatment $\cdot$ Heterogeneous Fenton type reactions · Recalcitrant compounds · Kinetics

Extended author information available on the last page of the article 


\section{Introduction}

Cellulose, hemicelluloses, and lignin are the main components of wood. Cellulose is a polymer consisting of D-glucopyranosyl units. Hemicelluloses are a mixed group of both linear and branched sugars heteropolymers. Lignin is an amorphous, aromatic, water-insoluble, heterogeneous, three-dimensional, and cross-linked polymer. Wood has also other minor components named as extractives, as they are easily extracted by water or solvents. One of the usual processing of wood for printing paper production is the alkaline sulfite pulping process, in which wood chips are impregnated with sodium hydroxide and sodium sulfite ( $\mathrm{pH}$ 9-10), and they are subsequently mechanically refined. This treatment, named as chemimechanical process, combines chemical action prior to mechanical action. Since the chemical charge and the organic dissolved matter is not enough as to implement a chemical recovery system, diluted spent liquors are generally treated in the effluent system [1-5].

Advanced Oxidation Processes (AOP) have proved to be interesting options to degrade or mineralize hazardous compounds present in this kind of effluent. These processes differ from each other in the source of radicals
$\mathrm{HO}$, which is their main feature. Hydroxyl radicals (HO-) present high reactivity and low selectivity during oxidation [1], [6-9].

Classical Fenton was developed in the 1890s and consists of iron species combined with hydrogen peroxide to oxidize organic matter [10]. Iron catalysts require strong acidic conditions $(\mathrm{pH}<4)$ to avoid leaching and sludge formation. On the contrary, the copper-based catalyst can work within a broad range of $\mathrm{pH}$ and offer good operational stability, so they are an excellent choice for the degradation and oxidation of organic recalcitrant matter [11] (see Table 1).

Heterogeneous catalysts use solid supports to deposit the active phase which activates the $\mathrm{H}_{2} \mathrm{O}_{2}$, thereby avoiding the complexity and economical cost of separate the catalyst from the reaction medium. Among the possible options, mesoporous $\gamma-\mathrm{Al}_{2} \mathrm{O}_{3}$ presents high surface area and strong interactions active phase-support. As support of $\mathrm{CuO}$ particles, it minimizes copper ions leaching into the reaction medium [23-25].

No information has been found regarding the application of the system $\mathrm{CuO} / \gamma-\mathrm{Al}_{2} \mathrm{O}_{3}-\mathrm{H}_{2} \mathrm{O}_{2}$ on effluents from the industrial alkaline sulfite treatment of wood, known as chemimechanical pulping. As these processes do not have a chemical recovery system, spent liquors are generally discharged into the receiving body. The catalytic oxidation

Table 1 Summary of several copper-based systems which have been used in oxidation reactions

\begin{tabular}{|c|c|c|c|c|}
\hline Catalyst & Target compound & Experimental conditions & Outcomes & Ref \\
\hline $\mathrm{CuSO}_{4}$ & Benzylic alcohols (3 mmol) & $\begin{array}{l}1 \mathrm{~mol} \% \text { of catalyst, } 1 \mathrm{~mL} \text { of } \mathrm{H}_{2} \mathrm{O}_{2}[30 \%] \text {, } \\
80{ }^{\circ} \mathrm{C}\end{array}$ & Conversion $=90 \%$ & {$[12]$} \\
\hline Copper oxide nanoparticles & $\begin{array}{l}\text { Methylene blue, basic cationic dye, } \\
(14.4 \mu \mathrm{M})\end{array}$ & $\begin{array}{l}1.0 \pm 0.1 \mathrm{mg} \text { of catalyst, } 0.15 \mathrm{~mL} / \mathrm{min} \text { of } \\
\mathrm{H}_{2} \mathrm{O}_{2}, 25^{\circ} \mathrm{C}\end{array}$ & Conversion $>90 \%$ & {$[13]$} \\
\hline $\mathrm{Cu} / \mathrm{MCM}-41$ & Phenol (100 mg/L) & $\begin{array}{l}0.15 \mathrm{~g} \text { of catalyst, } 0.306 \mathrm{ml} \text { of } \mathrm{H}_{2} \mathrm{O}_{2} \\
\text { [35\%], } 20^{\circ} \mathrm{C} \text {, UV of } 8 \mathrm{~W} \text { and } 365 \mathrm{~nm}\end{array}$ & Conversion $>70 \%$ & {$[14]$} \\
\hline$[\mathrm{Cu}($ sal-ambmz)Cl]-zeolite & Styrene $(0.005 \mathrm{~mol})$ & $\begin{array}{l}15 \mathrm{mg} \text { of catalyst, } 0.15 \mathrm{mmol} \text { of } \mathrm{H}_{2} \mathrm{O}_{2} \\
{[30 \%], 75^{\circ} \mathrm{C}}\end{array}$ & Conversion $=56.7 \%$ & {$[15]$} \\
\hline$[\mathrm{Cu}($ sal-ambmz)Cl]-zeolite & $\begin{array}{l}\text { Methyl phenyl sulfide } \\
(0.005 \mathrm{~mol})\end{array}$ & $\begin{array}{l}5 \mathrm{mg} \text { of catalyst, } 0.005 \mathrm{mmol} \text { of } \mathrm{H}_{2} \mathrm{O}_{2} \\
{[30 \%], 75^{\circ} \mathrm{C}}\end{array}$ & Not reported & {$[15]$} \\
\hline$[\mathrm{Cu}($ sal-ambmz)Cl]-zeolite & Phenol (0.05 mol) & $\begin{array}{l}25 \mathrm{mg} \text { of catalyst, } 0.05 \mathrm{~mol} \mathrm{H}_{2} \mathrm{O}_{2}[30 \%] \\
80{ }^{\circ} \mathrm{C}\end{array}$ & Conversion $=42 \%$ & {$[15]$} \\
\hline Copper complexes & $\begin{array}{l}\text { Methyl orange, azo dye } \\
\left(210^{-5} \mathrm{M}\right)\end{array}$ & $\begin{array}{l}3.1110^{-6} \mathrm{M} \text { of catalyst, } 2.4010^{-2} \mathrm{M} \text { of } \\
\mathrm{H}_{2} \mathrm{O}_{2} \text {, UV light, } 300 \mathrm{~W}\end{array}$ & Conversion $=80 \%$ & {$[16]$} \\
\hline Ordered mesoporous $\mathrm{CuFe}_{2} \mathrm{O}_{4}$ & Imidacloprid (10 mg/L) & $\begin{array}{l}0.3 \mathrm{~g} / \mathrm{L} \text { of catalyst, } 40 \mathrm{mM} \text { of } \mathrm{H}_{2} \mathrm{O}_{2} \\
{[30 \%], 30{ }^{\circ} \mathrm{C}}\end{array}$ & Conversion $>90 \%$ & {$[17]$} \\
\hline $\mathrm{Cu}_{2}(\mathrm{OH}) \mathrm{PO}_{4}$ & Direct Brown $2\left(\left(\mathrm{NH}_{4}\right)_{2} \mathrm{HPO}_{4}\right)(20 \mathrm{mg} / \mathrm{L})$ & $\begin{array}{l}100 \mathrm{mg} \text { of catalyst, } 0.8 \mathrm{~mL} \text { of } \mathrm{H}_{2} \mathrm{O}_{2} \\
{[30 \%], 50^{\circ} \mathrm{C}}\end{array}$ & Conversion $=93.2 \%$ & {$[18]$} \\
\hline $\mathrm{CuO} / \gamma-\mathrm{Al}_{2} \mathrm{O}_{3}$ & Phenol (200 mg/L) & $\begin{array}{l}20 \mathrm{~g} / \mathrm{L} \text { of catalyst, } 15 \mathrm{mM} \text { of } \mathrm{H}_{2} \mathrm{O}_{2} \\
{[30 \%], 70^{\circ} \mathrm{C}}\end{array}$ & Conversion $=97 \%$ & {$[19]$} \\
\hline $\mathrm{CuSO}_{4} /$ glucaric acid & $\begin{array}{l}\text { Remazol Brilliant Blue R, Anthraqui- } \\
\text { none }(100 \mathrm{mg} / \mathrm{L})\end{array}$ & $\begin{array}{l}10 \mathrm{mM} / 15 \mathrm{mM} \text { of catalyst, } 200 \mathrm{mM} \text { of } \\
\mathrm{H}_{2} \mathrm{O}_{2}[30 \%]\end{array}$ & Conversion $=98 \%$ & {$[20]$} \\
\hline $\mathrm{CuO} / \gamma-\mathrm{Al}_{2} \mathrm{O}_{3}$ & Black 5, azo dye (100 mg/L) & $\begin{array}{l}0.20 \mathrm{~g} \text { of catalyst, } 40 \mathrm{mM} \text { of } \mathrm{H}_{2} \mathrm{O}_{2} \\
{[30 \%], 21^{\circ} \mathrm{C}}\end{array}$ & Removal $=90 \%$ & {$[21]$} \\
\hline $\mathrm{CuO} / \mathrm{Li}_{2} \mathrm{O}-\gamma-\mathrm{Al}_{2} \mathrm{O}_{3}$ & Methylene blue (0.025 mM) & $\begin{array}{l}33.6 \mathrm{mg} / \mathrm{L} \text { of the copper active phase, } \\
0.05 \mathrm{M} \text { of } \mathrm{H}_{2} \mathrm{O}_{2}[30 \%], 25^{\circ} \mathrm{C}\end{array}$ & Conversion $>90 \%$ & {$[22]$} \\
\hline
\end{tabular}


of mixed recalcitrant compounds in industrial effluents is unusual because of the complexity of the effluents and the high costs involved in the total mineralization of the organic matter. Nevertheless, the conversion of recalcitrant to easily degradable compounds and the recovery of the catalysts can make the difference. Therefore, the study of the behavior of the industrial effluent with this oxidative system and the determination of the kinetic parameters for its application is a key step for the subsequent design of a treatment plant.

The amount and complex nature of compounds formed as intermediates during the oxidation process make extremely difficult the identification and quantification of the individual reactions produced during oxidation. The aim of this work was to propose a kinetic model for the reactions involved in the heterogeneous copper-based Fenton-type oxidation of mixed recalcitrant compounds in an industrial effluent from the alkaline sulfite treatment of wood, using Total Organic Carbon (TOC) as representative of the quantitative evolution of organic matter throughout oxidation.

Homogeneous systems are more efficient in the oxidation of compounds because of the single phase [26], [27]. Studying this system allows to know the maximum conversion (always considering that metal species are different in both systems) and to check for mass transfer resistance as result of the introduction of another phase. Homogeneous copperbased oxidations were, therefore, analyzed to verify the catalyst effect on the oxidation rate and to evaluate eventual mass transfer limitations because of the heterogeneous system.

Adsorption on the support as result of attractive forces is always possible [28], so it is also important to verify whether TOC reduction is only produced by oxidation or if there is any adsorption component, and how it varies at different temperature and $\mathrm{pH}$ conditions.

\section{Materials and methods}

\section{Industrial effluent}

The study involved a pulp and paper integrated mill, "Papel Prensa S.A.", located in San Pedro, Argentina, which produces 132,000 ton/year of soda-sulfite chemimechanical pulps from a mixture of willows, poplar, and eucalyptus, and recycled newspaper. The effluent of the mill comprises several streams: (1) liquid waste from deinking plant; (2) water from wood treatment; (3) black liquor from the chemical treatment of wood ( $\mathrm{pH} 7-8$, deep red color, mainly composed of extractives and lignin derived from the product of the chemical reaction between wood and pulping liquor); (4) effluent from chemimechanical pulp washing; (5) effluent from the bleaching plant; (6) white water from the paper making section. As stream 3 contains the highest polluting load, this work was performed simulating the effluent with dilutions of spent liquor 3), using a liquor/water ratio of $1 / 50$. The liquor was stored in plastic containers and it was used without filtration. The temperature of this real effluent in the point of the treatment is about $60-70^{\circ} \mathrm{C}$.

\section{Synthesis and characterization of supported catalysts}

Commercial $\gamma-\mathrm{Al}_{2} \mathrm{O}_{3}$ (SASOL) pellets $(1.8 \mathrm{~mm}$ in diameter and $200 \mathrm{~m}^{2} / \mathrm{g}$ of surface area) were used as support and were impregnated using an aqueous solution of $\mathrm{Cu}\left(\mathrm{NO}_{3}\right) \cdot 2.5 \mathrm{H}_{2} \mathrm{O}$ (Riedel-de Haën, p.a.) as precursor. The incipient wetness impregnation method comprises mixing the support with an aqueous solution containing an appropriate amount of salt so that, after calcination, the catalyst contains the required metal content. The volume of the prepared solution is equal or slightly smaller than the pore volume of the support. The maximum load is limited by the solubility of the precursor in the solution. Solids were air dried for $24 \mathrm{~h}$, oven dried during $24 \mathrm{~h}$ at $120^{\circ} \mathrm{C}$, and finally calcined during $4 \mathrm{~h}$ at $900{ }^{\circ} \mathrm{C}$ in air atmosphere.

The support and the catalysts were characterized using the following techniques: Surface areas were calculated from $\mathrm{N}_{2}$ adsorption isotherms at $-196{ }^{\circ} \mathrm{C}$. Oxide structures and cluster size of the synthesized metal oxides supported on alumina were determined by techniques of powder XRD. The main peaks corresponding to the aluminum oxide (gamma phase) are $2 \theta=66.7^{\circ}(100), 46.1^{\circ}(80), 37.4^{\circ}(60)$, and $39.7^{\circ}(30)$. The surface morphology and elemental composition of the catalysts were examined by means of a scanning electron microscope (SEM) and by energy dispersive $\mathrm{X}$-ray spectroscopy (EDS).

The organic matter removal from the used catalysts was accomplished by Thermogravimetric Analysis, the measurements were carried out from 25 to $900{ }^{\circ} \mathrm{C}$ under air current $\left(20 \mathrm{~mL} / \mathrm{min} ; 10^{\circ} \mathrm{C} / \mathrm{min}\right)$. The nature of carbonaceous deposits was explored by Fourier-transformed infrared spectroscopy and recorded over the spectral range $4000-600 \mathrm{~cm}^{-1}$. Solid samples were prepared by the $\mathrm{KBr}$ pellet method.

\section{Fenton-type oxidations and adsorption trials}

The stoichiometric $\mathrm{H}_{2} \mathrm{O}_{2}$ concentration respect to the Chemical Oxygen Demand (COD) value was $1.98 \mathrm{~g} / \mathrm{L}$. It was calculated assuming complete mineralization of COD to $\mathrm{CO}_{2}$ and $\mathrm{H}_{2} \mathrm{O}$. The theoretical amount of hydrogen peroxide estimated for total TOC oxidation is $2.43 \mathrm{~g} / \mathrm{L}$. The studied initial doses of $\mathrm{H}_{2} \mathrm{O}_{2}$ were: sub-stoichiometric I $(1.78 \mathrm{~g} / \mathrm{L}$; $\mathrm{H}_{2} \mathrm{O}_{2}$ :COD ratio of $\left.0.9: 1\right)$, over-stoichiometric II ( $2.43 \mathrm{~g} / \mathrm{L}$; $\mathrm{H}_{2} \mathrm{O}_{2}$ :COD ratio of 1.2:1), and over-stoichiometric III ( $3.54 \mathrm{~g} / \mathrm{L} ; \mathrm{H}_{2} \mathrm{O}_{2}:$ COD ratio of $1.8: 1$ ).

A PYREX glass batch reactor of $250 \mathrm{~mL}$ with a glass stopper equipped with a condenser, a thermocouple, and 
$\mathrm{pH}$ meter was used. To minimize external mass transport effects, experiments were carried out with a high-speed stirring. Testing was performed in contact with air, at atmospheric pressure. The reaction volume was $100 \mathrm{~mL}$.

Heterogeneous experiments were conducted using catalyst pellets. Initial time was recorded when the catalyst was added to the liquid inside the batch reactor, and the system reached the reaction temperature. Time zero was recorded when $\mathrm{H}_{2} \mathrm{O}_{2}$ was added, initiating the oxidation reaction.

A series of preliminary tests (blank trials) were carried out with the effluent and the support to be used for the preparation of the catalyst $\left(\gamma-\mathrm{Al}_{2} \mathrm{O}_{3}+\mathrm{H}_{2} \mathrm{O}_{2}+\right.$ industrial liquor; $\mathrm{H}_{2} \mathrm{O}_{2}+$ industrial liquor; $\gamma-\mathrm{Al}_{2} \mathrm{O}_{3}+$ industrial liquor). Due to the lack of background of the Fenton-type treatment for the oxidation of this kind of industrial liquor, the presence and/ or the influence of non-catalytic processes such as adsorption onto $\gamma-\mathrm{Al}_{2} \mathrm{O}_{3}$ were analyzed. In addition, the thermal decomposition of the liquor was analyzed under extreme temperature conditions $\left(80-85^{\circ} \mathrm{C}\right)$.

Adsorption studies of the industrial liquor- $\mathrm{CuO} / \gamma-\mathrm{Al}_{2} \mathrm{O}_{3}$ system were also performed without hydrogen peroxide addition.

Homogeneous oxidations were performed with $0.0365 \mathrm{~g}$ of $\mathrm{Cu}\left(\mathrm{NO}_{3}\right) \cdot 2.5 \mathrm{H}_{2} \mathrm{O}$ (Riedel-de Haën, p.a.), equivalent to $100 \mathrm{ppm}$ of supported copper used in heterogeneous reactions.

Liquid samples of $2.5 \mathrm{~mL}$ were taken according to appropriate time intervals and were immediately analyzed. Total oxidation time was $240 \mathrm{~min}$. The analyzed response throughout the reaction was the percentage of total organic carbon reduction (TOC $\%$ reduction).

\section{Analytical methods}

Solids were determined according to Tappi T629. The inorganic content was assessed by determining the ashes at $525{ }^{\circ} \mathrm{C}$ according to Tappi T211. The color of the effluent was measured by the absorbance at $450 \mathrm{~nm}$ (TECHCOMP spectrometer). COD was measured following the technique SM 5220-B (Standard Methods for the Examination of Water and Wastewater, 17th edition). Organic acids and peroxide consumption during the reaction, were quantified by HPLC (Waters Corp. Massachusetts, USA) using an Aminex-HPX87H column under the following conditions: $4 \mathrm{mM} \mathrm{H}_{2} \mathrm{SO}_{4}$ as eluent, flow rate of $0.6 \mathrm{~mL} / \mathrm{min}, 35^{\circ} \mathrm{C}$, and UV Diode Array detector (organic acids at $210 \mathrm{~nm}$ and aromatic compounds at $254 \mathrm{~nm}$ ). Total Organic Carbon (TOC) technique was used to measure the organic compounds, using a TOC analyzer (Shimadzu, TOC-VCPN model).

\section{Kinetic study of Fenton-type reactions}

The rate and the order of the heterogeneous catalytic oxidation reactions were obtained using the linear form of " $n$ " order reactions. The order of the reaction was determined by fitting the equations to the experimental data, verifying the coefficient of determination $\left(R^{2}\right)$. Statgraphics software was used for curves fitting.

\section{Results and discussion}

\section{Effluent characterization}

Initial TOC and COD of the simulated effluent were $433 \mathrm{mg} / \mathrm{L}$ and $931 \mathrm{mg} / \mathrm{L}$, respectively. The main characteristics of the industrial spent liquor are shown in Table 2.

The hardwood mixture used by the mill is characterized by their extractives rich in hydrolyzable tannins, condensed tannins, flavonoid-based steroids (some esterified with fatty acids) and triterpenes. The industrial effluent contains sugars, low molecular weight polyoses, and several recalcitrant compounds to microbiological treatment. COD of stream 3 is composed mainly of aromatic derivatives from extractives and labile lignin fractions, and acetic acid, most of them with unknown chemical structure [1].

\section{Catalyst characterization}

The analysis of X-ray diffraction (Fig. 1) of calcined $\mathrm{CuO} / \gamma$ $\mathrm{Al}_{2} \mathrm{O}_{3}$ catalyst (before and after reaction) revealed only the presence of the characteristic peaks of the $\gamma-\mathrm{Al}_{2} \mathrm{O}_{3}$ phase, probably due to the low concentration of impregnated active phase and its good dispersion onto the support [29]. Despite the high calcination temperatures, the effects of sintering by the thermal treatment were negligible, evidenced by the final BET area of the homemade catalyst $\left(170 \mathrm{~m}^{2} / \mathrm{g}\right)$. The composition of the prepared catalyst via spectrometry and

Table 2 Chemical characteristics of the spent liquor

\begin{tabular}{lll}
\hline Parameter & Value & $\mathrm{SD}$ \\
\hline Total soluble solids $(\mathrm{g} / \mathrm{L})$ & 61.1 & 0.0 \\
$\mathrm{pH}$ & 7.4 & 0.0 \\
$\mathrm{COD}(\mathrm{mg} / \mathrm{L})$ & 46,550 & 0.1 \\
TOC $(\mathrm{mg} / \mathrm{L})$ & 21,665 & 0.3 \\
Ashes at $525^{\circ} \mathrm{C}(\%$ of total soluble & 52.3 & 0.0 \\
$\quad$ solids) & & \\
Acetic acid $(\mathrm{g} / \mathrm{L})$ & 23.6 & 0.0 \\
Formic acid $(\mathrm{g} / \mathrm{L})$ & 0.3 & 0.0 \\
Propionic acid $(\mathrm{g} / \mathrm{L})$ & 0.6 & 0.0 \\
\hline
\end{tabular}

$S D$ standard deviation 


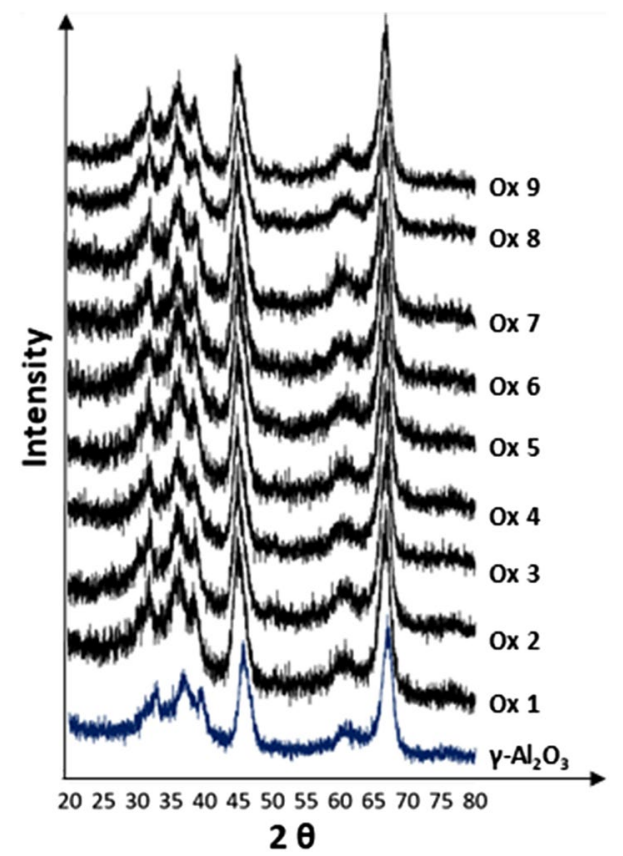

Fig. 1 XRD pattern for the catalyst used in the kinetic study (Ox1 to Ox 9 are defined bellow in Table 3 )

energy dispersive X-ray determined by surface mapping and as the average of 330 points from the surface to the center of the pellets is shown in Fig. 2. Active phase remained almost constant through all the distance, indicating a uniform distribution of copper species [30]. This diffusion of active species to inner zones of the support is probably a consequence of the high calcination temperature [31]. According to Fig. 2, the average pore size is nearly identical to the alumina support, indicating adequate diffusion of copper species.

\section{Kinetic study of TOC evolution by heterogeneous oxidation}

The control trials performed showed a negligible TOC conversion (less than $0.3 \%$ of conversion in all trials), therefore, there is no adsorption mechanism onto the catalytic support. No thermal decomposition of the liquor was verified (evidenced by the negligible TOC and COD reduction of the liquor). Catalyst mass and active phase content were analyzed in a previous work through an experimental design, to find their impact on TOC and COD reductions. Between the two tested points, the catalyst mass did not have a significant effect on TOC and COD reduction, and the higher active phase tested showed better performance in oxidation trials [32], then, $0.5 \mathrm{~g} / \mathrm{L}$ of $2.5 \% \mathrm{CuO} / \gamma-\mathrm{Al}_{2} \mathrm{O}_{3}$ were used.

The identified species in the chemimechanical black liquor (such as acetic acid, oxalic acid, sulfur compounds, sodium carbonate and other salts) [4], [5] are recalcitrant and interfere the Fenton oxidation process [33], avoiding a total mineralization [34], [35]. As complete mineralization would be then very expensive to achieve, the intention of this work was to reduce the organic content of the effluent (not its complete elimination), allowing the application of this process at the mills. As a consequence, initial doses of $\mathrm{H}_{2} \mathrm{O}_{2}$ were applied considering the feasibility of reducing costs.

The reaction temperature and $\mathrm{H}_{2} \mathrm{O}_{2}$ concentration are critical issues in Fenton and Fenton-type reactions [36], [37]. Since the oxidant reagent depletion is one of the main factors that influences oxidation efficiency, oxidation reaction conditions for the kinetic study were analyzed in terms of hydrogen peroxide consumption trough the " $\eta$ parameter" used by several authors [38], [39]. It is defined here as the reagent consumption, considered as the amount of TOC $(\mathrm{mg} / \mathrm{L})$ and COD $(\mathrm{mg} / \mathrm{L})$ converted per unit of consumed $\mathrm{H}_{2} \mathrm{O}_{2}(\mathrm{~g} / \mathrm{L})$.

Substantial amounts of hydrogen peroxide were still present at the end of the experience at low temperature, reflecting a slow formation of radicals with the concomitant low reductions of TOC and COD (Fig. 3). On the contrary, high temperatures contribute to a faster copper-catalyzed conversion of $\mathrm{H}_{2} \mathrm{O}_{2}$ into radicals, which enhances black liquor oxidation degree, evidenced by high TOC and COD conversions [38].

The percentage of lixiviated copper was also reported in Fig. 3. Some authors state that the reactivity of the compounds to be treated is the main cause of leaching in heterogeneous reactions [40]. The optimum $\mathrm{pH}$ to prevent $\mathrm{Cu}$ from leaching from the support is close to neutrality [11] [41], Since the $\mathrm{pH}$ of the reactions oscillates between 6 and 7, it is possible that leaching is a consequence of the compounds reactivity. The catalytic reactions could have some homogeneous contributions if the leached copper is still catalytically active. According to Fig. 3, a strategy to reduce leaching is to increase the severity of the conditions of reaction, which also prevents the accumulation of compounds on the surface of the catalyst. This is a plausible option since unproductive reactions were not verified in the working conditions as the use of $\mathrm{H}_{2} \mathrm{O}_{2}$ was still efficient and the analyzed parameters (for example, COD) decreased. However, as the effect of copper leaching on the heterogeneous kinetic analysis was out of the scope of this study, homogeneous catalysis contributions are not going to be taken into account when determining heterogeneous kinetics models. Leaching of copper and its influence on TOC, COD and $\mathrm{H}_{2} \mathrm{O}_{2}$ reduction, are subject of a future work.

According to TOC evolution with time, two different tendencies of TOC depletion were found (Fig. 4): (1) An abrupt decrease up to 0.1 min (named "seconds stage"); (2) A smooth decrease from 0.1 to 240 min (named "minutes stage").

This mechanism probably indicates that the "seconds stage" corresponds to higher-order kinetics, and/or other 

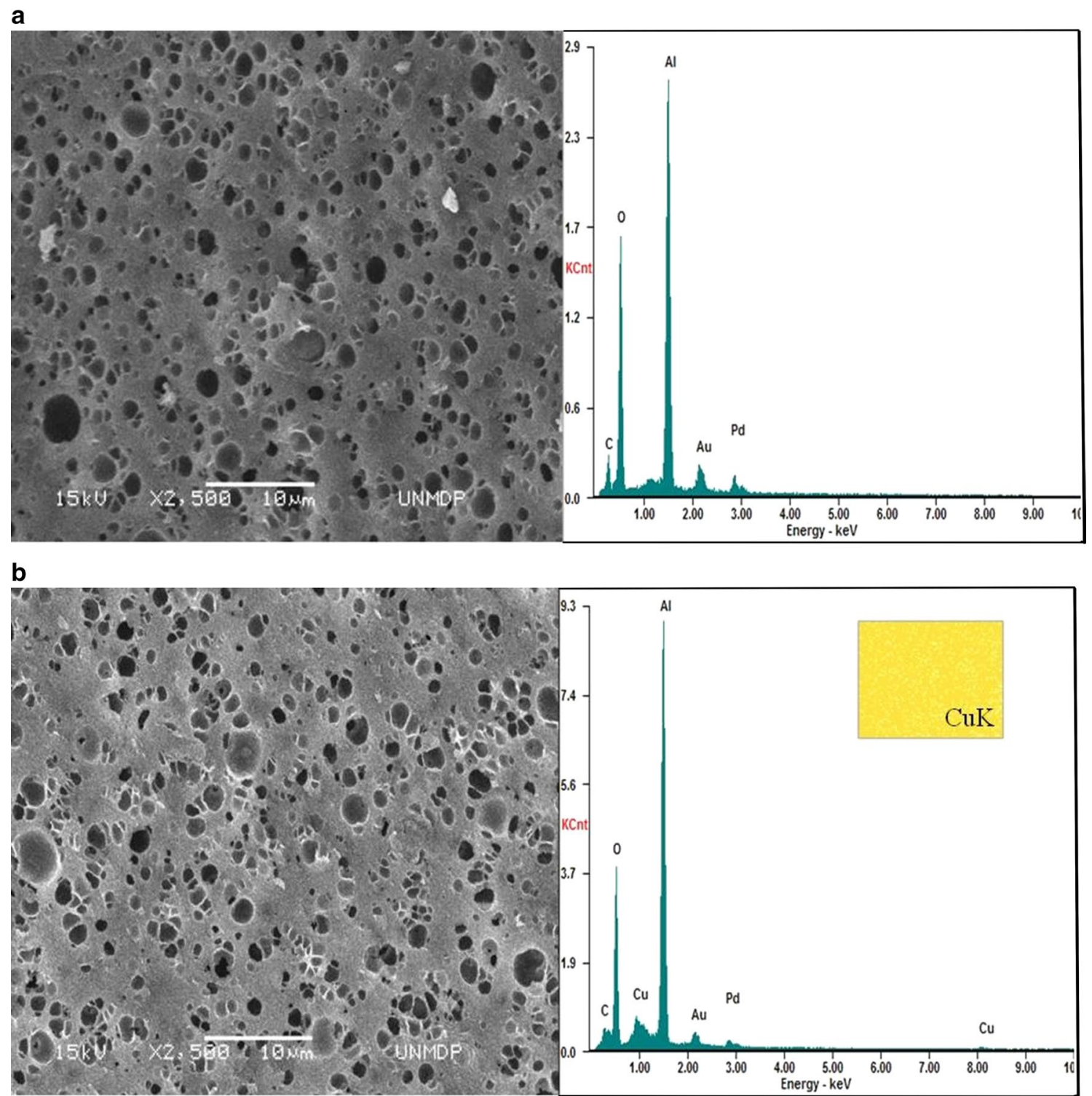

Fig. 2 SEM $(\times 2500)$ image, EDS spectra and surface mapping of a. $\gamma-\mathrm{Al}_{2} \mathrm{O}_{3}$ and b. $\mathrm{CuO} / \gamma-\mathrm{Al}_{2} \mathrm{O}_{3}$ catalyst

reaction mechanisms take place [42]. The "two-step kinetic model" [43] which can be applied to TOC reduction, admits two sequential steps of oxidation, suggesting that reactions should be responsible for TOC degradation [44]. The reactions could be represented as follows:

$\mathrm{A}+\mathrm{H}_{2} \mathrm{O}_{2} \stackrel{k_{s s}}{\rightarrow} \mathrm{B}$

$\mathrm{B}+\mathrm{H}_{2} \mathrm{O}_{2} \stackrel{k_{m s}}{\rightarrow} \mathrm{C}$

Where unstable species easily oxidized are named as A, pollutants that are difficult to oxidize are designed as $\mathrm{B}$, the desired final products $\left(\mathrm{CO}_{2}\right.$ and $\left.\mathrm{H}_{2} \mathrm{O}\right)$ are commonly referred as $\mathrm{C} ; k_{\mathrm{ss}}$ and $k_{\mathrm{ms}}$ correspond to the "seconds stage" and the "minutes stage" kinetics constants, respectively.

As can be seen in Fig. 4, the rapid decrease in TOC concentration observed within the first $0.1 \mathrm{~min}$ approximately is so fast that would require specialized equipment and a more exhaustive analysis, to determine the order and the exact mechanism of the reaction.

TOC reduction during the first $0.1 \mathrm{~min}$ is a direct consequence of the severity of the initial conditions. The decrease during the first $0.1 \mathrm{~min}$ is attributed to the oxidation of extremely easily oxidizable compounds present in the black liquor. The same trend is observed during tests in homogeneous phase (discussed below). Unlike what happens in 


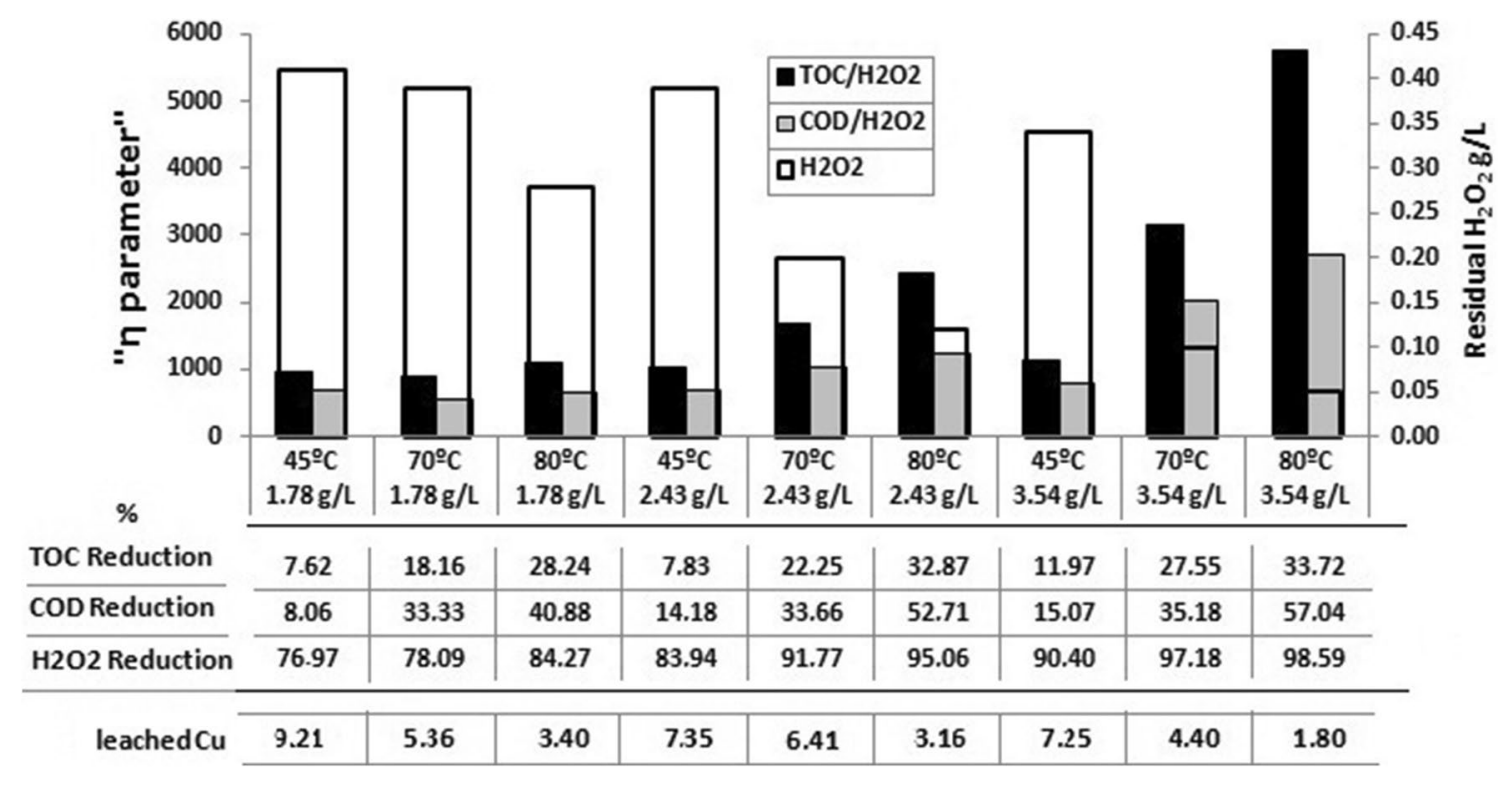

Fig. 3 " $~ \eta$ parameter" at different temperatures and $\mathrm{H}_{2} \mathrm{O}_{2}$ doses

the oxidation reaction, this trend is not observed during the adsorption process (reaction without $\mathrm{H}_{2} \mathrm{O}_{2}$ ), so this TOC decrease should not be attributed to the adsorption of organic compounds on the catalyst surface (also discussed below).

This "two-step" kinetic behavior was also observed by other authors [45], who found that the kinetics of COD removal in a real stream (mix of several compounds) by heterogeneous Fenton oxidation presents an initial abrupt decrease of COD, followed by a smooth one. The "seconds stage" oxidation rate is fast probably due to the great availability of active sites in the catalyst [46]. The critical aspect of heterogeneous systems probably is the reaction between $\mathrm{H}_{2} \mathrm{O}_{2}$ and supported copper (Fig. 5). At the beginning of the reaction, all active sites on the surface are available, so $\mathrm{HO}$ - production and oxidation of the recalcitrant compounds occurs fast [47]. As the oxidation proceeds, the reaction in the pores is partially blocked, as evidenced by the slow reaction rate in the "minutes stage".

Considering $\mathrm{TOC}_{\mathrm{A}}$ as the initial TOC value, $\mathrm{TOC}_{\mathrm{B}}$ represents its value immediately after the "seconds stage".

Simple regression models for the "seconds stage" were tested to determine $\mathrm{TOC}_{\mathrm{B}}$ dependence of the reaction conditions for each experimental point. TOC reduction was found to obey the following equation, where "Temp" is the working temperature, and " $\left[\mathrm{H}_{2} \mathrm{O}_{2}\right]_{0}$ " is the initial concentration of hydrogen peroxide $\left(R^{2}: 0.982\right)$ :

$$
\mathrm{TOC}_{B}=\frac{1}{\left(2.21 * 10^{-3}+1.13 * 10^{-6} * \mathrm{Temp} *\left[\mathrm{H}_{2} \mathrm{O}_{2}\right]_{0}\right)}
$$

Figure 6 compares the experimental and predicted TOC values from the "seconds stage", confirming the validity of the model.

Time-concentration curves for TOC reduction obtained for the oxidation reactions in the "minutes stage" period were fitted to potential models to obtain kinetic equations. In all cases, the oxidation rates can be described by pseudo-zero order kinetics. This kinetic model was observed at catalyst surface saturation by the reactants [48] and suggests that the rate of reaction in this study does not vary with the concentration of organic components.

Since the oxidation kinetics of the studied effluent corresponds to a pseudo-zero order model, some assumptions are needed to develop the kinetics analysis. It is assumed that HO. concentration reach a virtually constant value [49], that is, HO. concentration is considered in a pseudo steady-state condition [50]. The global kinetic of the reaction can be represented as follows:

$-\frac{\mathrm{d} C}{\mathrm{~d} t}=-r=k_{O H}[\mathrm{HO} \cdot]=k$

Where " $C$ " represents the concentration of TOC species in Eq. (2), " $r$ " is the reaction rate, " $k_{\mathrm{OH}}$ " is reaction kinetic rate constant and " $k_{\mathrm{ms}}$ " is the apparent pseudo-zero order kinetic constant.

Thus, the kinetic reaction for the "minutes stage" can be represented as (the parameter $R_{\mathrm{H}_{2} \mathrm{O}_{2}}$ in the following equation is defined bellow, in Eq. 6):

$$
-r_{\mathrm{TOC}_{C}}=-\frac{\mathrm{dTOC}_{B}}{\mathrm{~d} t}=\frac{k_{\mathrm{ms}}}{R_{\mathrm{H}_{2} \mathrm{O}_{2}}}
$$


Fig. 4 TOC evolution at different reaction temperatures $(45$, 70 and $80{ }^{\circ} \mathrm{C}$ ) and initial $\mathrm{H}_{2} \mathrm{O}_{2}$ concentration $(1.78,2.43$ and $3.54 \mathrm{~g} / \mathrm{L})$
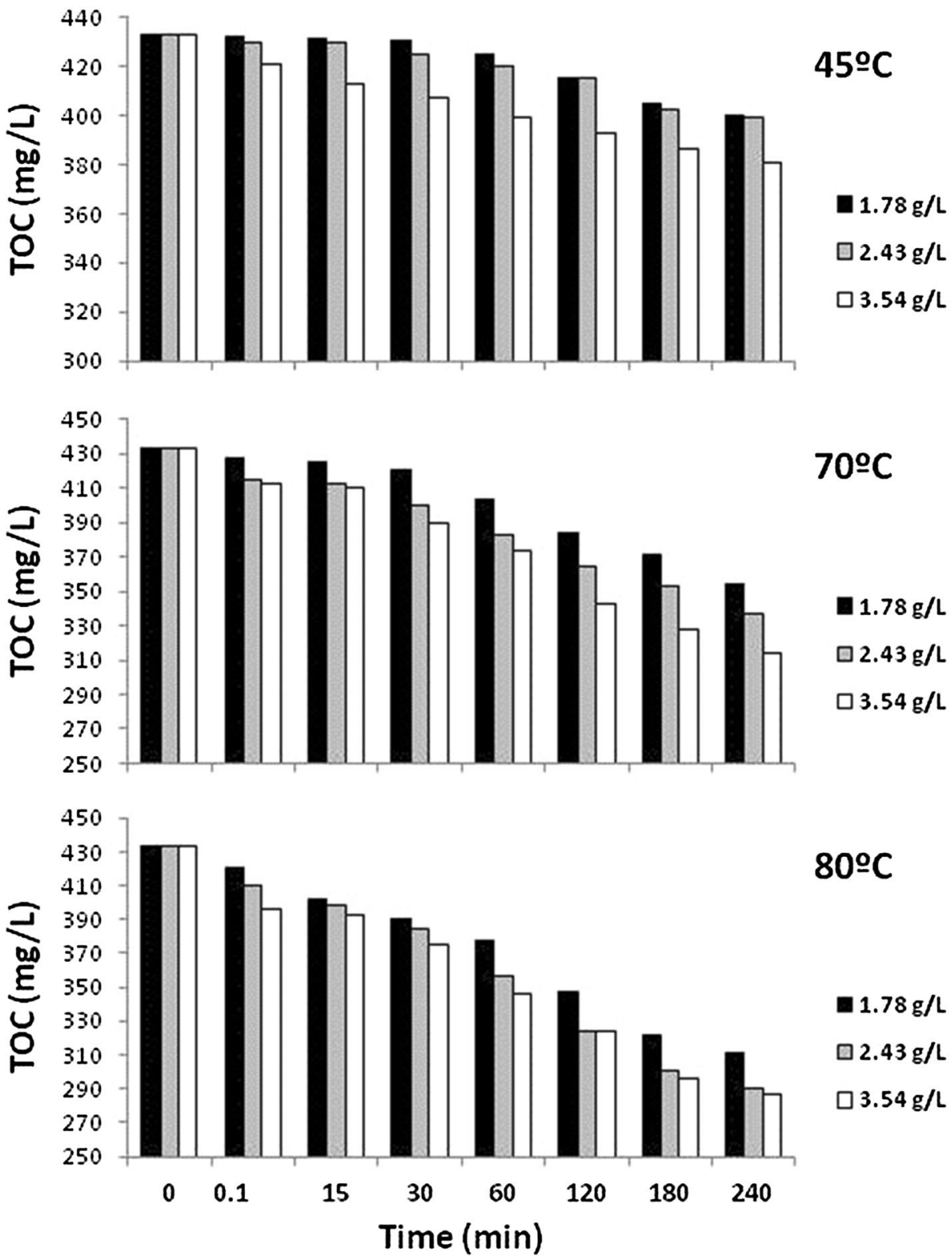

To assess the feasibility of reducing the treatment cost by reducing the $\mathrm{H}_{2} \mathrm{O}_{2}$ charge, a committed relationship between the maximization of $\mathrm{H}_{2} \mathrm{O}_{2}$ efficiency and the highest possible levels of TOC conversion was sought (Fig. 2). $R_{\mathrm{H}_{2} \mathrm{O}_{2}}$ can be defined as the ratio between the working hydrogen peroxide concentration " $\left[\mathrm{H}_{2} \mathrm{O}_{2}\right]_{0 \text {. Work }}$ " and the over-stoichiometric concentration III " $\left[\mathrm{H}_{2} \mathrm{O}_{2}\right]_{0}$ Over-stochiometricIII", as:

$R_{\mathrm{H}_{2} \mathrm{O}_{2}}=\frac{\left[\mathrm{H}_{2} \mathrm{O}_{2}\right]_{\text {OWork }}}{\left[\mathrm{H}_{2} \mathrm{O}_{2}\right]_{\text {OOver - stochiometric III }}}$

The final kinetic expression can be obtained from the integration of the Eq. (5) as follow:
$\mathrm{TOC}_{\mathrm{C}}=\mathrm{TOC}_{\mathrm{B}}-\frac{k_{\mathrm{ms}}}{R_{\mathrm{H}_{2} \mathrm{O}_{2}}} *$ time

Where $\mathrm{TOC}_{\mathrm{B}}$ is the initial Total Organic Carbon of the minutes stage, and $\mathrm{TOC}_{\mathrm{C}}$ is the final Total Organic Carbon at a certain time. Since this model does not discriminate between the refractory pollutants (mainly acetic acid) and oxidizable compounds in the initial mixture, the remaining TOC along the reaction is due to the presence of both.

Percentages of TOC reduction after 240 min of oxidation and kinetic constants of the respective equations at different experimental conditions are shown in Table 3. All catalytic reactions were accomplished without $\mathrm{pH}$ adjustment to record the natural tendency of the catalyst system. 


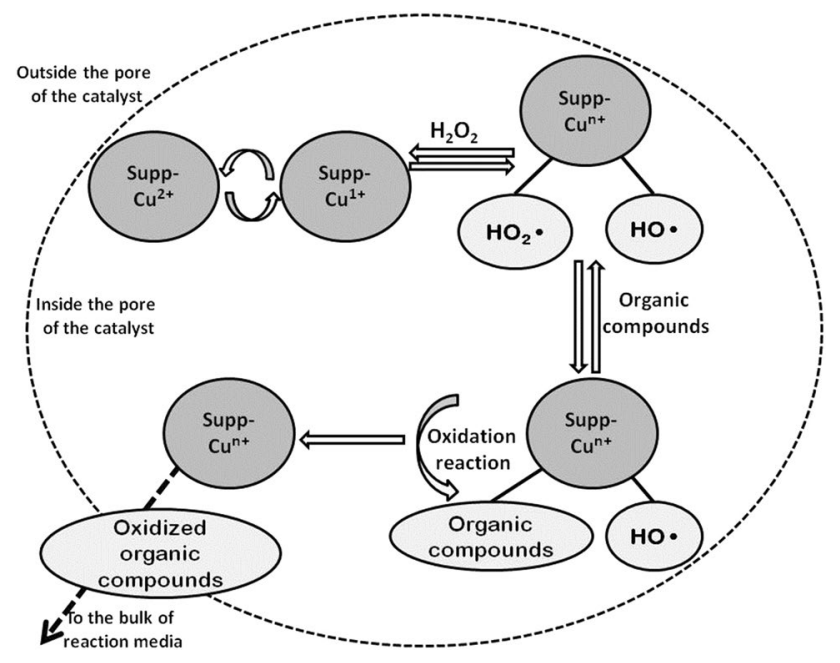

Fig. 5 Proposed mechanism of the oxidation reaction between $\mathrm{H}_{2} \mathrm{O}_{2}$ and supported copper Adapted from [22], [47]

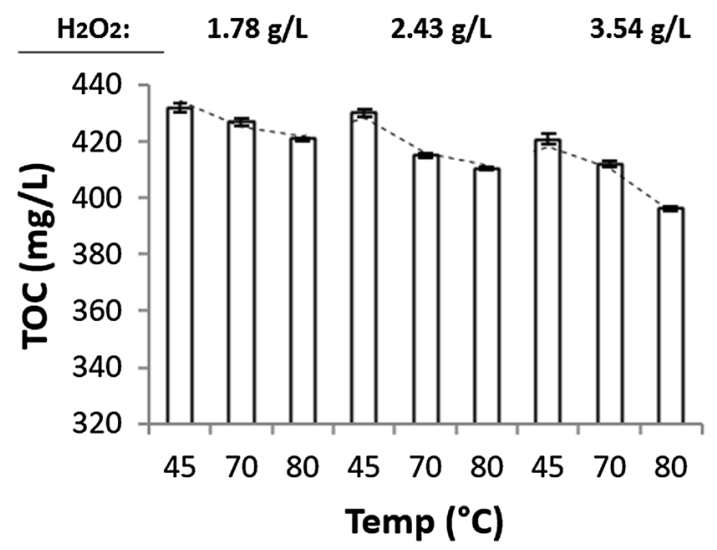

Fig. 6 Parity plot for TOC in the "seconds stage". The bars correspond to the experimental values, and the dotted lines correspond to the values calculated with the model

The $\mathrm{pH}$ values of the oxidation reactions were close to 7.3 in all cases, possibly due to both the recalcitrance of liquor compounds and to the interference of acetic acid and oxalic acid (presents as sodium salts), sulfur compounds, sodium carbonate and other salts on Fenton oxidation.

The Arrhenius expression, showing the relationship between the reaction temperature and the specific kinetic rate is expressed as follows:

$k=A \mathrm{e}^{\left(-\frac{E}{R * \text { Temp }}\right)}$

Where

" $k$ " is the kinetic rate constant $(\mathrm{mg} / \mathrm{L} \mathrm{min})$.

" $A$ " is the Arrhenius factor ( $\mathrm{mg} / \mathrm{L} \mathrm{min})$.

" $E$ " is the Arrhenius activation energy $(\mathrm{J} / \mathrm{mol})$.
Table 3 TOC reduction after $240 \mathrm{~min}$ of reaction and experimental kinetic constants of the "minutes stage" reactions for each experimental condition

\begin{tabular}{lllcll}
\hline Trial & Temp $\left({ }^{\circ} \mathrm{C}\right)$ & {$\left[\mathrm{H}_{2} \mathrm{O}_{2}\right](\mathrm{g} / \mathrm{L})$} & \% TOC Red $^{\mathrm{a}}$ & $k_{\mathrm{ms}}^{\mathrm{b}}$ & $R^{2}$ \\
\hline Ox 1 & 45 & 1.78 & 7.62 & 0.145 & 0.977 \\
Ox 2 & 70 & 1.78 & 18.16 & 0.313 & 0.983 \\
Ox 3 & 80 & 1.78 & 28.24 & 0.447 & 0.963 \\
Ox 4 & 45 & 2.43 & 7.83 & 0.136 & 0.977 \\
Ox 5 & 70 & 2.43 & 22.25 & 0.329 & 0.965 \\
Ox 6 & 80 & 2.43 & 32.87 & 0.513 & 0.944 \\
Ox 7 & 45 & 3.54 & 11.97 & 0.151 & 0.917 \\
Ox 8 & 70 & 3.54 & 27.55 & 0.245 & 0.953 \\
Ox 9 & 80 & 3.54 & 33.72 & 0.479 & 0.947 \\
Ox 10 & 45 & 2.43 & 22.97 & 0.343 & 0.964 \\
Ox 11 & 70 & 2.43 & 41.45 & 0.416 & 0.907 \\
Ox 12 & 80 & 2.43 & 47.34 & 0.482 & 0.913 \\
\hline
\end{tabular}

Ox 1to Ox 9 corresponds to heterogeneous oxidations

Ox 10 to Ox 12 corresponds to homogeneous oxidations

${ }^{\text {a }}$ Total percentage of TOC reduction

${ }^{\mathrm{b}} k_{\mathrm{ms}}$ in $(\mathrm{mg} / \mathrm{L} \mathrm{min})$ for Ox 1 to $\mathrm{Ox} 9$, and $k_{\mathrm{ms}}$ in $(1 / \mathrm{min})$ for Ox 10 to Ox 12

" $R$ " is the gas constant $(8.314 \mathrm{~J} / \mathrm{mol} \mathrm{K})$.

"Temp" is the temperature of reaction (absolute).

Arrhenius activation energy indicates the minimum energy that the reactants must have for the reaction to proceed. It can also be interpreted as the energy barrier that molecules must overcome to transform reactants into products. For these oxidation processes the activation energy " $E$ " resulted to be $33.17 \mathrm{~kJ} / \mathrm{mol}$, obtained by plotting $\left(\ln k_{\mathrm{ms}} / R_{\mathrm{H}_{2} \mathrm{O}_{2}}\right)$ vs $(1 / \operatorname{Temp}(K))\left(R^{2}: 0.904\right)$.

The kinetic constant can be obtained from the experimental data as a function of the operating temperature by plotting $k_{\mathrm{ms}} v s$ Temp $(K)\left(R^{2}: 0.999\right)$, confirming that the process is governed by the Arrhenius law:

$k_{\mathrm{ms}}=2 * 10^{-6} * \mathrm{e}^{0.0356 * \operatorname{Temp}(K)}$

The relationship between experimental and predicted TOC values from the "minutes stage", confirm the validity of the model, as shown in Fig. 7.

The kinetic constants of the simulated effluent degradation are significantly affected by temperature and $\left[\mathrm{H}_{2} \mathrm{O}_{2}\right]_{0}$, being higher at high values of these two parameters (Table 3). As the applied thermal energy increases, the rate of reaction increases according to the Arrhenius law. In these conditions, diffusion of reactants to active sites of the catalyst and diffusion of product from the active sites back to the reaction medium are favored [51], [52]. The increase in rate constants with $\left[\mathrm{H}_{2} \mathrm{O}_{2}\right]_{0}$ suggests that the percentage of TOC removal increases with the ratio $\mathrm{H}_{2} \mathrm{O}_{2}$ : COD, due to the 

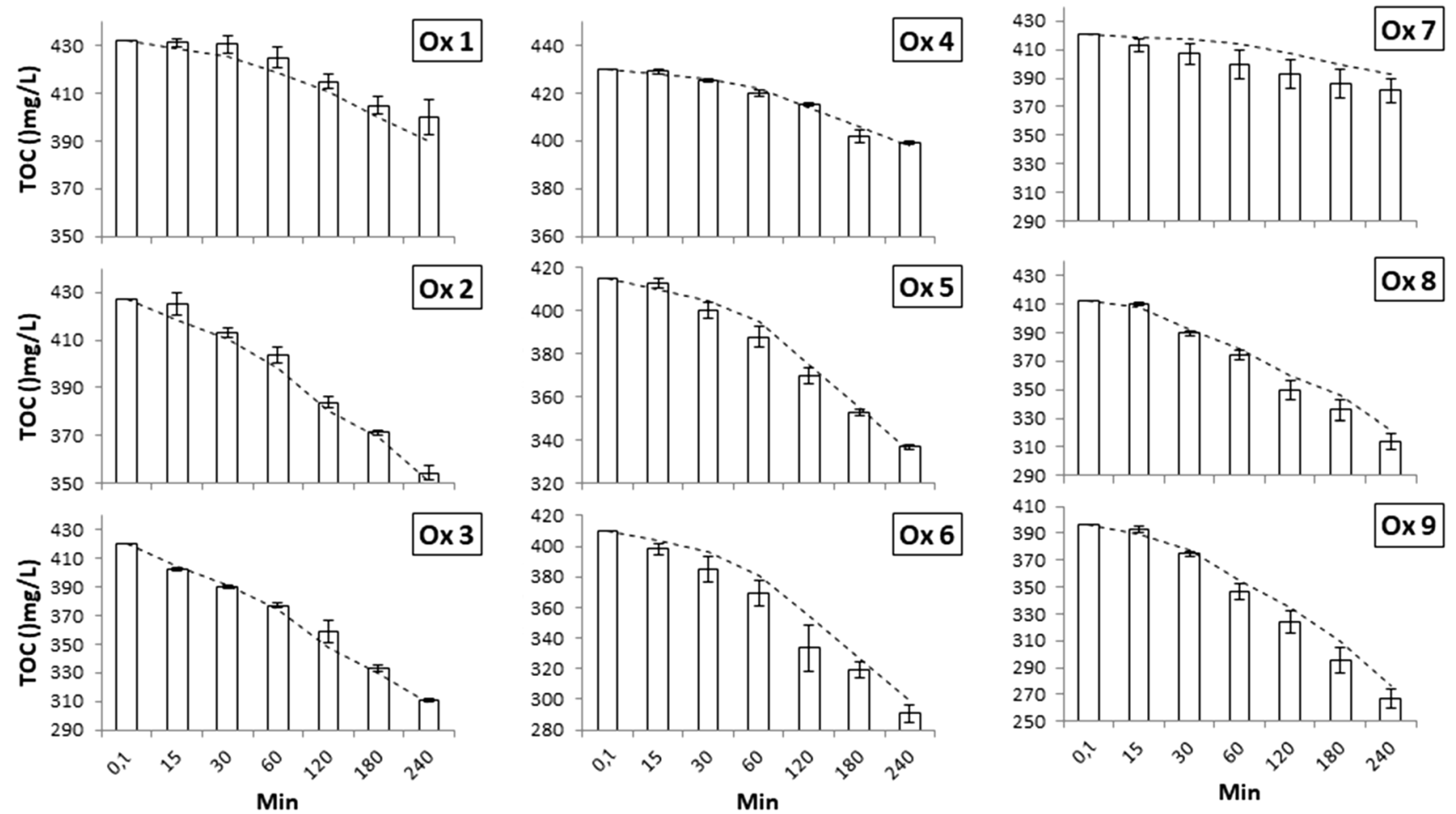

Fig. 7 Parity plot for TOC in the "minutes stage". The bars correspond to the experimental values, and the dotted lines correspond to the values calculated with the model

additional generation of HO- radicals [53]. No scavenging effect of $\mathrm{HO}$. was observed by $\mathrm{H}_{2} \mathrm{O}_{2}$ in all the studied range.

A set of experiments were carried out to determine the effect of catalyst load in the heterogeneous system. The surface rate constant $\left(k_{\text {suf }}\right)$ can be obtained from the ratio between the apparent rate constant for the minutes stage $\left(k_{\mathrm{ms}}\right)$ and the surface area of the catalyst [52].

$k_{\text {suf }}=\frac{k_{\mathrm{ms}}}{\mathrm{SA}_{v}}$

$\mathrm{SA}_{\mathrm{v}}=\mathrm{SA} * C_{\mathrm{Cu}}$

Where:

" $\mathrm{SA}_{\mathrm{v}}$ " is the catalyst surface area $\left(\mathrm{m}^{2} / \mathrm{L}\right)$.

"SA" is the specific surface area $\left(\mathrm{m}^{2} / \mathrm{g}\right)$.

" $C_{\mathrm{Cu}}$ " is the copper content.

The values of $k_{\mathrm{ms}}$ were proportional to copper oxide concentrations in the reaction mixture and increased linearly with the increase of catalyst concentration: $\mathrm{i}_{\mathrm{ms}}: 5.3910^{-04}$ for $0.1 \mathrm{~g} / \mathrm{L} ; k_{\mathrm{ms}}: 6.7610^{-04}$ for $0.3 \mathrm{~g} / \mathrm{L}$; and $k_{\mathrm{ms}}: 6.7610^{-04}$ for $0.5 \mathrm{~g} / \mathrm{L}$. Final TOC as function of the amount of catalyst at $70{ }^{\circ} \mathrm{C}$ and $\mathrm{H}_{2} \mathrm{O}_{2}$ over-stoichiometric II concentration (as defined in II) correspond to: $379.9 \mathrm{mg} / \mathrm{L}, 359.0 \mathrm{mg} / \mathrm{L}$, and $336.7 \mathrm{mg} / \mathrm{L}$, respectively.

The long-term stability was analyzed in a series of five consecutive reactions, without thermal treatment between reactions (performed at $70{ }^{\circ} \mathrm{C}$ and over-stoichiometric II concentration of $\mathrm{H}_{2} \mathrm{O}_{2}$ ). The catalysts used were filtered from the reaction medium (at the working temperature to prevent re-adsorption of compounds) and dried at room temperature during $24 \mathrm{~h}$. TOC and $\mathrm{H}_{2} \mathrm{O}_{2}$ concentration (in \% of reduction) at the end of each catalytic test can be seen in Fig. 8. Throughout the five cycles of oxidative treatment, a small induction phase was observed, which was more noticeable during the consecutive treatments. According to Fig. 8,

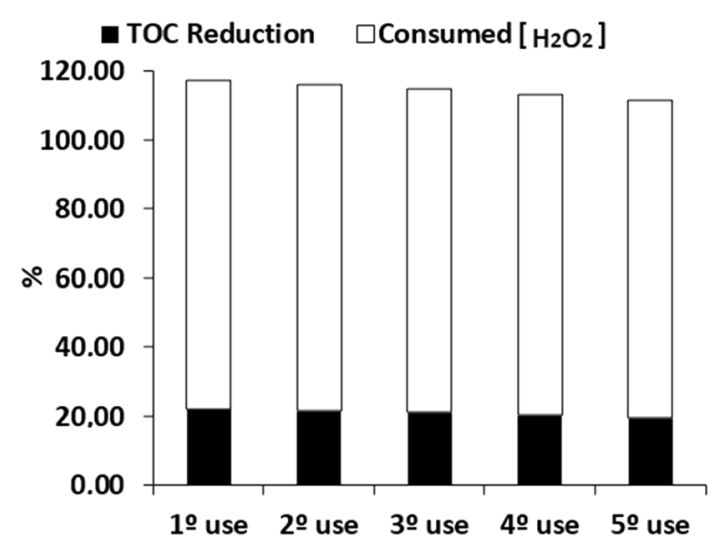

Fig. 8 TOC reduction and $\mathrm{H}_{2} \mathrm{O}_{2}$ consumed in five consecutive oxidation cycles 
the catalyst remains catalytically active, with respect to the elimination of TOC and the efficient consumption of the oxidizing agent.

\section{TOC reduction by homogeneous oxidations}

In homogeneous catalysis, the catalyst is the same phase that the organic matter to oxidize. In these systems, the highest possible conversion of TOC can be found. Homogeneous and heterogeneous oxidation rates and activation energies

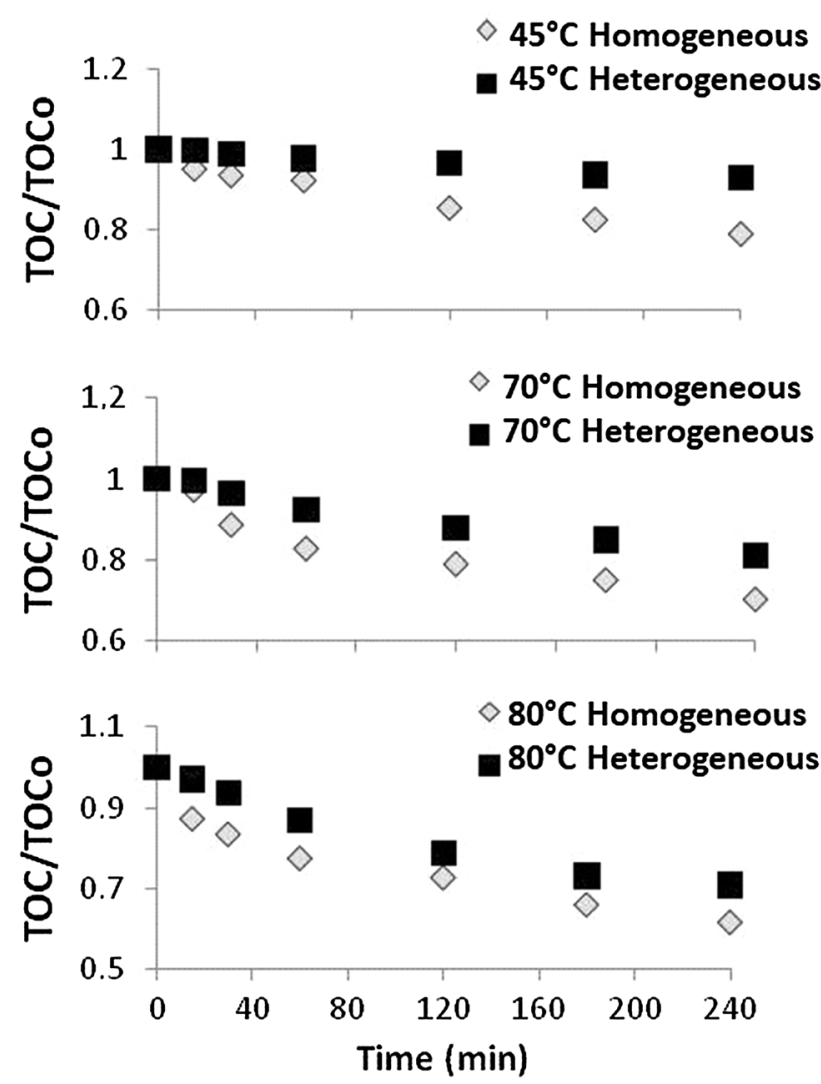

Fig. 9 Heterogeneous vs. Homogeneous oxidations (100 ppm of copper supported on $\gamma-\mathrm{Al}_{2} \mathrm{O}_{3}$ and in solution respectively, over-stoichiometric II doses of $\mathrm{H}_{2} \mathrm{O}_{2}$ in all trials) were then compared to see the efficiency of the studied heterogeneous system.

As in heterogeneous oxidations, the variation of total organic carbon versus time can be divided into two stages: the first, in which TOC decreases abruptly (from 0 up to $0.1 \mathrm{~min}$ of reaction), and the second, in which it decreases smoothly (from 0.1 min until the end of reaction time). The time-concentration curves for the second stage were fitted to a pseudo first-order kinetic model. Several authors have also found a "two-step" kinetic in the homogeneous oxidation of real effluent streams (a fast first stage followed by a slower second stage) [49], [44].

Activation energy in homogeneous experiments resulted to be $15.13 \mathrm{kJmol}^{-1}\left(R^{2}: 0.985\right)$. From the comparison of heterogeneous and homogeneous catalytic oxidations (see Fig. 9 and Table 3), it was confirmed that the reaction rate of heterogeneous oxidations was lower than that observed for the homogeneous ones, whereas the activation energy was higher, with the concomitant lower TOC conversion values. The results agree with those obtained by other authors [26], [54-56] and may be due to the reduced accessibility of $\mathrm{H}_{2} \mathrm{O}_{2}$ to copper, as the active phase is supported on $\gamma-\mathrm{Al}_{2} \mathrm{O}_{3}$.

\section{Estimation of TOC reduction by adsorption}

Adsorption experiences were accomplished to verify possible adsorption contributions during the oxidation reactions. The adsorption of the simulated effluent components onto the $\mathrm{CuO} / \gamma-\mathrm{Al}_{2} \mathrm{O}_{3}$ catalyst was evaluated by analyzing the system behavior at different $\mathrm{pH}$ and temperatures in absence of $\mathrm{H}_{2} \mathrm{O}_{2}$.

A set of experiments were carried out at $70{ }^{\circ} \mathrm{C}$ to analyze the relationship between the system $\mathrm{pH}$ and the adsorption of organic compounds over $\gamma-\mathrm{Al}_{2} \mathrm{O}_{3}$ (see Table 4). Trials were made as a function of the point of zero charge (PZC) of $\gamma-\mathrm{Al}_{2} \mathrm{O}_{3}$ (7-9), corresponding to the $\mathrm{pH}$ at which its surface is neutral [57], [58]. The $\mathrm{pH}$ of the experiments was controlled by adding $\mathrm{H}_{2} \mathrm{SO}_{4}$ or $\mathrm{NaOH}$ to the reaction volume; since $\gamma-\mathrm{Al}_{2} \mathrm{O}_{3}$ tends to dissolve in strong systems (either
Table 4 TOC reduction after $240 \mathrm{~min}$ of reaction and experimental kinetic constants for the adsorption reactions

\begin{tabular}{llllllr}
\hline Trial & Temp $\left({ }^{\circ} \mathrm{C}\right)$ & PH & $(\%)$ TOC Red & $k_{\text {ads }}^{\mathrm{a}}$ & \multicolumn{2}{c}{$R^{2}$} \\
\hline Ads 1 & 70 & 3 & 20.78 & - & - & 105.882 \\
Ads 2 & 70 & 5 & 12.14 & - & - & 61.882 \\
Ads 3 & 70 & 7 (Uncontrolled) & 9.49 & $4,18 \mathrm{E}-04$ & 0.986 & 48.352 \\
Ads 4 & 70 & 8 & 0.48 & - & - & 2.470 \\
Ads 5 & 70 & 10 & 2.86 & - & - & 14.588 \\
Ads 6 & 45 & 7 (Uncontrolled) & 11.06 & $5,09 \mathrm{E}-04$ & 0.966 & 56.352 \\
Ads 7 & 80 & 7 (Uncontrolled) & 9.12 & $3,87 \mathrm{E}-04$ & 0.968 & 46.470 \\
\hline
\end{tabular}

${ }^{\mathrm{a}} k_{\text {ads }}$ in $(1 / \mathrm{min})$

${ }^{\mathrm{b}} q$ in $\mathrm{mg} / \mathrm{m}^{2}$ 
acidic or basic), these trials were performed within a $\mathrm{pH}$ range that was kept between 3 and 10 .

At $\mathrm{pH}$ values lower or higher than the $\mathrm{PZC}$, the surface is increasingly protonated or deprotonated, respectively [59]. Because negligible adsorption over the catalyst was verified at $\mathrm{pH} 8$ it can be presumed that this $\mathrm{pH}$ value might correspond to the $\mathrm{PZC}$ of $\mathrm{CuO} / \gamma-\mathrm{Al}_{2} \mathrm{O}_{3}$ system (see Table 4). Nevertheless, when initial $\mathrm{pH}$ was adjusted to 3 TOC reduction was higher than at $\mathrm{pH} 7$. When initial $\mathrm{pH}$ increased to 7, the adsorption performances exhibit a continuous decreasing tendency along with the rise of $\mathrm{pH}$, probably due to electrostatic attraction (Table 4) [60]. The spent liquor from the alkaline treatment of wood behaves as an anionic stream, which is easily adsorbed on the active sites of the alumina surface, highly protonated at low $\mathrm{pH}$ [61]. On the contrary, the adsorption is less favored at high $\mathrm{pH}$ because of the great amount of $\mathrm{OH}^{-}$ions in alumina surface [62]. In this conditions, more active sites at the surface are available for the catalyzed decomposition of $\mathrm{H}_{2} \mathrm{O}_{2}$ [63]. As oxidation trials in this study were carried out at near neutral $\mathrm{pH}$, adsorption by $\mathrm{pH}$ effect can be considered as negligible.

The effect of temperature on the adsorption of organic matter of the simulated effluent onto the $\mathrm{CuO} / \gamma-\mathrm{Al}_{2} \mathrm{O}_{3}$ system was studied by carrying out temperature-controlled experiments $\left(45,70\right.$ and $\left.80{ }^{\circ} \mathrm{C}\right)$. The percentage of TOC removal decreased with increasing temperature (Table 4), evidencing an exothermic process [64], [65]. Some authors argue that molecules tend to pass from the solid phase to the bulk phase when increasing temperature [66]. The amount of adsorbed compounds increased during the $240 \mathrm{~min}$ of reaction (no plateau was observed), so saturation of catalyst surface was not reached under the studied conditions.

The amount of adsorbed organic compounds ( $\mathrm{q}, \mathrm{mg} / \mathrm{m}^{2}$ ) was calculated by the equation:

$q=\frac{\left(\mathrm{TOC}_{0}-\mathrm{TOC}\right) * V}{C_{\mathrm{Cu}} * \mathrm{SA}}$

Where $\mathrm{TOC}_{\mathrm{o}}$ is the initial concentration of total organic carbon in solution, TOC $(\mathrm{mg} / \mathrm{L})$ is the concentration at a specific time and $V(\mathrm{~L})$ is the volume of reaction (Table 4). The time-concentration curves for the adsorption experiments were fitted to a pseudo first-order kinetic model. The magnitude of the activation energy indicates whether the adsorption is mainly physical $(5-40 \mathrm{~kJ} / \mathrm{mol})$ or chemical (40-800 kJ/mol) [67], [68]. TOC depletion due to adsorption processes was best described by a pseudo first-order kinetic model and the activation energy resulted to be $7.32 \mathrm{~kJ} / \mathrm{mol}$ $\left(R^{2}: 0.941\right)$, which confirms the nature of physisorption onto the $\mathrm{CuO} / \gamma-\mathrm{Al}_{2} \mathrm{O}_{3}$ surface.

Oxidation experiments were carried out assuming that TOC decreased only by an oxidation mechanism, that is, without considering an eventual adsorption of organic

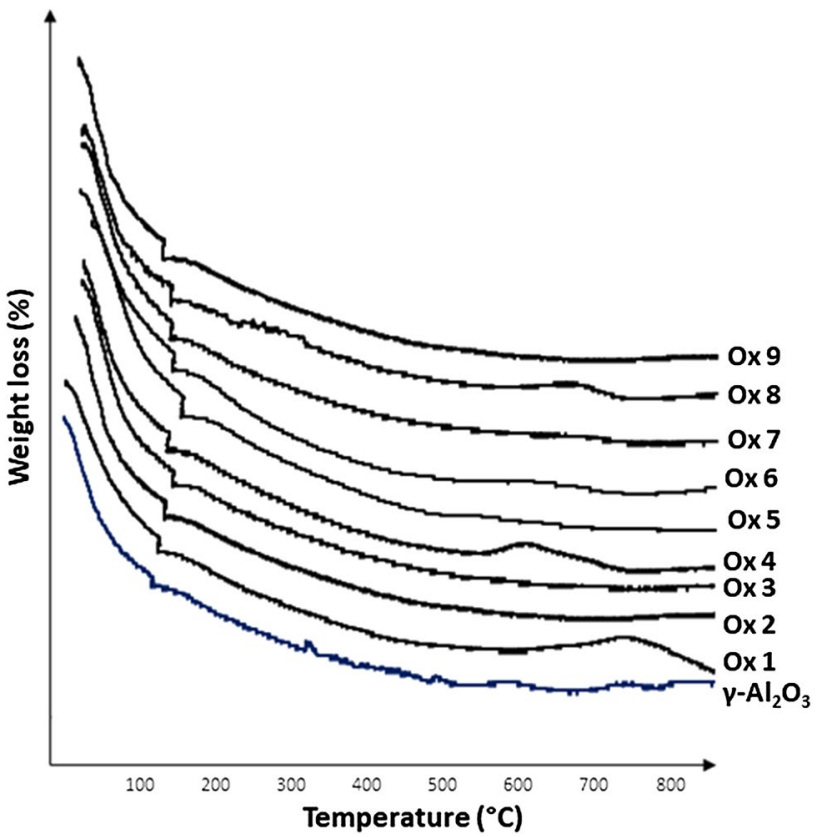

Fig. 10 TG curves for used catalysts in the oxidation trials

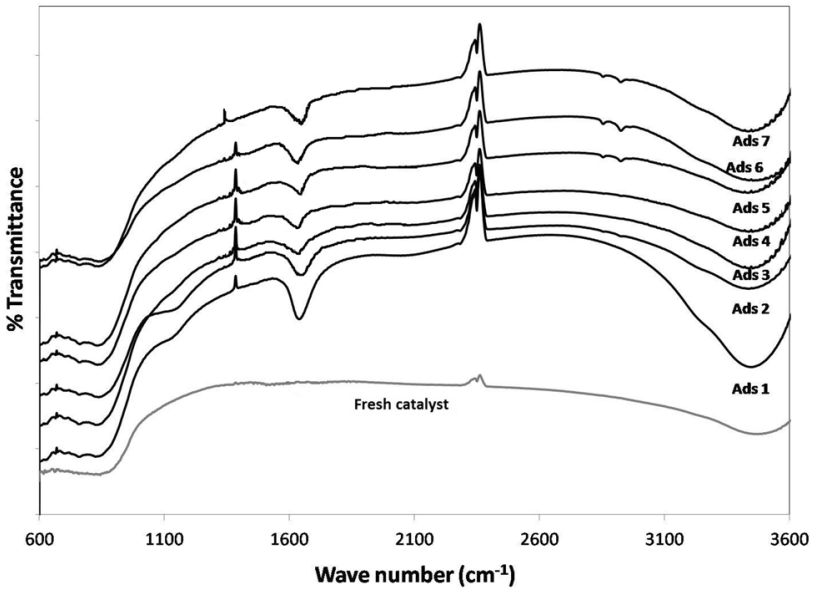

Fig. 11 FTIR spectra of $\mathrm{CuO} / \gamma-\mathrm{Al}_{2} \mathrm{O}_{3}$ catalyst, used in adsorption trials

compounds on the catalyst. The veracity of this assumption was assessed by the thermogravimetric characterization of catalysts from all trials. The TGA profiles (Fig. 10) showed two main steps: the release of pre-adsorbed water (near $150^{\circ} \mathrm{C}$ ) and the loss of reversible carbonaceous deposits (near $500{ }^{\circ} \mathrm{C}$ ) [69]. In case of oxidations trials (Ox 1 to Ox 9), a mass loss of nearly $1 \%$ was registered (in the range of $400-600{ }^{\circ} \mathrm{C}$ ). Thermogravimetric curves show an increase in mass loss according to the experimental conditions described previously.

Catalysts used in all adsorption trials were characterized by FTIR to determine the nature of adsorbed organic 
compounds (see Fig. 11). The shoulder at $833 \mathrm{~cm}^{-1}$ indicates the presence of $\gamma-\mathrm{Al}_{2} \mathrm{O}_{3}$ [70]. Bands around $1618 \mathrm{~cm}^{-1}$ are probably due to the combination of aromatic $\mathrm{C}=\mathrm{C}$ and conjugated carbonyl $\mathrm{C}=\mathrm{O}$ stretching [51]. The amount of adsorbed compounds decreases as the $\mathrm{pH}$ increases, which is evidenced by the reduction in the intensity of the bands. This effect agrees with results presented in Table 4 (Ads 1 to Ads 5). Temperature effect over the amount adsorbed compounds onto the catalyst (Ads 3, 6 and 7) was in accordance with the experimental conditions described previously. Bands around $2300 \mathrm{~cm}^{-1}$ correspond to $\mathrm{CO}_{2}$ due to atmospheric carbon dioxide that could be removed from the spectra [71]. Samples after calcination present $\mathrm{O}-\mathrm{H}$ stretching vibration evidenced by the bands around $3430 \mathrm{~cm}^{-1}$ representing a strong hydrophilicity [60].

Based on these results, adsorption effects over the $\mathrm{CuO} /$ $\gamma-\mathrm{Al}_{2} \mathrm{O}_{3}$ surface cannot be neglected. Important differences are observed between these results and those of the control trials as shown in Table 4. This difference in the results of the adsorption test corresponds to differences in a number of compounds adsorbed on the surface of the catalyst, before and after impregnation of the active phase [28]. Several authors attribute this high amount of organic adsorbed compounds onto the active phase $/ \gamma-\mathrm{Al}_{2} \mathrm{O}_{3}$ system to the crystalline structure of the active phase (dependent on the impregnated copper load and the calcination temperature), which could exhibit vacant, to accommodate neutral molecules or compounds with anionic characteristics, while $\gamma-\mathrm{Al}_{2} \mathrm{O}_{3}$ has a virtually zero adsorption capacity [72].

\section{Conclusions}

A two-step kinetic model was applied to TOC reduction in heterogeneous and homogeneous oxidations, admitting two sequential steps of oxidation, a first fast stage ("seconds stage") followed by a slow one ("minutes stages").

The heterogeneous oxidation process was evaluated by examining temperature and catalyst loading. Temperature affected dramatically the reaction and the kinetics constant increased linearly with the increase of catalyst load. The oxidation rate in the "minutes stage" can be described by a pseudo-zero order kinetics and the activation energy resulted to be $33.17 \mathrm{~kJ} / \mathrm{mol}$.

TOC conversions and reaction rates of homogeneous oxidations were higher than those observed for the heterogeneous reactions, confirming mass transfer limitation. The homogeneous oxidation rate for the "minutes stage" was fitted to a pseudo first-order kinetic model and the activation energy resulted $15.13 \mathrm{~kJ} / \mathrm{mol}$.

The simulated effluent from the alkaline treatment of wood behaves as an anionic stream, with an easy adsorption to the active sites of alumina surface at lower $\mathrm{pH}$.
Adsorption of organic compounds onto $\mathrm{CuO} / \gamma-\mathrm{Al}_{2} \mathrm{O}_{3}$, of physical nature and exothermic, cannot be neglected. It was best described by a pseudo first order kinetic model with an activation energy of $7.32 \mathrm{~kJ} / \mathrm{mol}$.

Acknowledgements To the Consejo Nacional de Investigaciones Científicas y Técnicas (CONICET) for the doctoral scholarship, and to the Agencia Nacional de Promoción Científica y Tecnológica (ANPCyT) for the financial support.

\section{Compliance with ethical standards}

Conflict of interest The authors declare no competing financial interest.

Open Access This article is distributed under the terms of the Creative Commons Attribution 4.0 International License (http://creativeco mmons.org/licenses/by/4.0/), which permits unrestricted use, distribution, and reproduction in any medium, provided you give appropriate credit to the original author(s) and the source, provide a link to the Creative Commons license, and indicate if changes were made.

\section{References}

1. Meza P, Felissia FE, Area MC (2010) Reduction of the recalcitrant COD of high yield pulp mills effluents by AOP. Part 1. Combination of ozone and activated sludge. BioResources 6(2):1053-1068

2. Pokhrel D, Viraraghavan T (2004) Treatment of pulp and paper mill wastewater-a review. Sci Total Environ 333(1-3):37-58

3. Kamali M, Khodaparast Z (2015) Review on recent developments on pulp and paper mill wastewater treatment. Ecotoxicol Environ Saf 114:326-342

4. Area MC, Valade JL (1998) Revisión de la composición de los licores residuales de los procesos de pulpado y su aprovechamiento. El Papel La Rev Pap para España y América Lat 1:67-70

5. Area MC, Valade JL (1998) Hacia una utilización integral de la madera. Revisión de los procesos de pulpado con acción química. El Papel. La Rev Pap para España y América Lat 1:47-51

6. Andreozzi R, Caprio V, Insola A, Marotta R (1999) Advanced oxidation processes (AOP) for water purification and recovery. Catal Today 53:51-59

7. Covinich LG, Bengoechea DI, Fenoglio RJ, Area MC (2014) Advanced oxidation processes for wastewater treatment in the pulp and paper industry : a review. Am J Environ Eng 4(3):56-70

8. Hermosilla D, Merayo N, Gascó A, Blanco Á (2014) The application of advanced oxidation technologies to the treatment of effluents from the pulp and paper industry: a review. Environ Sci Pollut Res 22(1):168-191

9. Collivignarelli MC, Pedrazzani R, Sorlini S, Abbà A, Bertanza G (2017) $\mathrm{H}_{2} \mathrm{O}_{2}$ based oxidation processes for the treatment of real high strength aqueous wastes. Sustainability 9(2):1-14

10. Martinez NSS, Fernadez JF, Segura XF, Ferrer AS (2003) Preoxidation of an extremely polluted industrial wastewater by the Fenton's reagent. J Hazard Mater 101(3):315-322

11. Covinich LG, Massa P, Fenoglio RJ, Area MC, Covinich LG, Massa P, Fenoglio RJ, Area MC (2016) Oxidation of hazardous compounds by heterogeneous catalysis based on $\mathrm{Cu} / \mathrm{Al} 2 \mathrm{O} 3$ system in Fenton-type reactions. Crit Rev Environ Sci Technol 46(23-24):1745-1781 
12. Ahmad JU, Räisänen MT, Leskelä M, Repo T (2012) Copper catalyzed oxidation of benzylic alcohols in water with $\mathrm{H}_{2} \mathrm{O}_{2}$. Appl Catal A Gen 411-412:180-187

13. Angi A, Sanli D, Erkey C, Birer Ö (2014) Catalytic activity of copper (II) oxide prepared via ultrasound assisted Fenton-like reaction. Ultrason Sonochem 21(2):854-859

14. Hu X, Lam F, Cheung L, Chan K, Zhao X (2001) Copper/MCM41 as catalyst for photochemically enhanced oxidation of phenol by hydrogen peroxide. Catal Today 68:129-133

15. Maurya MR, Chandrakar AK, Chand S (2007) Oxidation of phenol, styrene and methyl phenyl sulfide with $\mathrm{H} 2 \mathrm{O} 2$ catalysed by dioxovanadium(V) and copper(II) complexes of 2-aminomethylbenzimidazole-based ligand encapsulated in zeolite-Y. J Mol Catal A Chem 263(1-2):227-237

16. Fei B-L, Yan Q-L, Wang J-H, Liu Q-B, Long J-Y, Li Y-G, Shao K-Z, Su Z-M, Sun W-Y (2014) Green oxidative degradation of methyl orange with copper(II) schiff base complexes as photofenton-like catalysts. Z Anorg Allg Chem 640(10):2035-2040

17. Wang Y, Zhao H, Li M, Fan J, Zhao G (2014) Magnetic ordered mesoporous copper ferrite as a heterogeneous Fenton catalyst for the degradation of imidacloprid. Appl Catal B Environ 147:534-545

18. Zhan Y, Li H, Chen Y (2010) Copper hydroxyphosphate as catalyst for the wet hydrogen peroxide oxidation of azo dyes. J Hazard Mater 180(1-3):481-485

19. Jibril BY, Atta AY, Al-Waheibi YM, Al-Waheibi TK (2013) Effect of copper loadings on product selectivities in microwaveenhanced degradation of phenol on alumina-supported copper oxides. J Ind Eng Chem 19:1800-1804

20. Verma P, Shah V, Baldrian P, Gabriel J, Stopka P, Trnka T, Nerud F (2004) Decolorization of synthetic dyes using a copper complex with glucaric acid. Chemosphere 54(3):291-295

21. Bradu C, Frunza L, Mihalche N, Avramescu S-M, Neaţă M, Udrea I (2010) Removal of reactive black 5 azo dye from aqueous solutions by catalytic oxidation using $\mathrm{CuO} / \mathrm{Al} 2 \mathrm{O} 3$ and $\mathrm{NiO} / \mathrm{Al} 2 \mathrm{O} 3$. Appl Cata B Environ 96(3-4):548-556

22. Ndolomingo MJ, Meijboom R (2015) Kinetic analysis of catalytic oxidation of methylene blue over $\gamma-\mathrm{Al}_{2} \mathrm{O}_{3}$ supported copper nanoparticles. Appl Catal A Gen 506:33-43

23. Zhang G, Wang S, Zhao S, Fu L, Chen G, Yang F (2011) Oxidative degradation of azo dye by hydrogen peroxide electrogenerated in situ on anthraquinonemonosulphonate/polypyrrole composite cathode with heterogeneous $\mathrm{CuO} / \gamma-\mathrm{Al}_{2} \mathrm{O}_{3}$ catalyst. Appl Catal B Environ 106(3-4):370-378

24. Caudo S, Centi G, Genovese C, Perathoner S (2007) Copper- and iron-pillared clay catalysts for the WHPCO of model and real wastewater streams from olive oil milling production. Appl Catal B Environ 70(1-4):437-446

25. Lyu L, Zhang L, Wang Q, Nie Y, Hu C (2015) Enhanced fenton catalytic efficiency of \#-Cu-A12O3 by $\sigma-\mathrm{Cu} 2^{+}$-ligand complexes from aromatic pollutant degradation. Environ Sci Technol 49:8639-8647

26. Punzi M, Mattiasson B, Jonstrup M (2012) Treatment of synthetic textile wastewater by homogeneous and heterogeneous photoFenton oxidation. J Photochem Photobiol A Chem 248:30-35

27. Zapico RR, Marín P, Díez FV, Ordóñez S (2015) Influence of operation conditions on the copper-catalysed homogeneous wet oxidation of phenol: development of a kinetic model. Chem Eng J 270:122-132

28. Doumic L, Salierno G, Cassanello M, Haure P, Ayude M (2015) Efficient removal of orange $\mathrm{G}$ using Prussian Blue nanoparticles supported over alumina. Catal Today 240:67-72

29. Kim S-K, Kim K-H, Ihm S-K (2007) The characteristics of wet air oxidation of phenol over $\mathrm{CuOx} / \mathrm{Al} 2 \mathrm{O} 3$ catalysts: effect of copper loading. Chemosphere 68(2):287-292
30. Lekhal A, Glasser BJ, Khinast JG (2001) Impact of drying on the catalyst profile in supported impregnation catalysts. Chem Eng Sci 56:4473-4487

31. Di Luca C, Ivorra F, Massa P, Fenoglio R (2012) Alumina supported fenton-like systems for the catalytic wet peroxide oxidation of phenol solutions. Ind Eng Chem Res 51(26):8979-8984

32. Covinich L, Felissia F, Fenoglio R, Area MC (2017) Removal of recalcitrant organic compounds from an industrial complex effluent by heterogeneous Fenton-type treatment. Clean Soil Air Water 45(3): 1500451

33. Brillas E (2014) A review on the degradation of organic pollutants in waters by UV photoelectro-fenton and solar photoelectrofenton. J Braz Chem Soc 25(3):393-417

34. Zazo JA, Casas JA, Molina CB, Quintanilla A, Rodriguez JJ (2007) Evolution of ecotoxicity upon Fenton's oxidation of phenol in water. Environ Sci Technol 41(20):7164-7170

35. Pignatello JJ, Oliveros E, MacKay A (2006) Advanced oxidation processes for organic contaminant destruction based on the Fenton reaction and related chemistry. Crit Rev Environ Sci Technol 36(1):1-84

36. Zeinaly F, Shakhes J, Zeinali N (2013) Multi stage peroxide and activated peroxide bleaching of kenaf bast pulp. Carbohydr Polym 92(2):976-981

37. Santos MSF, Alves A, Madeira LM (2011) Paraquat removal from water by oxidation with Fenton's reagent. Chem Eng J 175:279-290

38. Zazo JA, Pliego G, Blasco S, Casas JA, Rodriguez JJ (2011) Intensification of the Fenton process by increasing the temperature. Ind Eng Chem Res 50:866-870

39. Inchaurrondo NS, Massa P, Fenoglio R, Font J, Haure P (2012) Efficient catalytic wet peroxide oxidation of phenol at moderate temperature using a high-load supported copper catalyst. Chem Eng J 198-199:426-434

40. Inchaurrondo N, Cechini J, Font J, Haure P (2012) Strategies for enhanced CWPO of phenol solutions. Appl Catal B Environ 111-112:641-648

41. Bokare AD, Choi W (2014) Review of iron-free Fenton-like systems for activating $\mathrm{H} 2 \mathrm{O} 2$ in advanced oxidation processes. J Hazard Mater 275:121-135

42. Buffle M-O, Schumacher J, Salhi E, Jekel M, von Gunten U (2006) Measurement of the initial phase of ozone decomposition in water and wastewater by means of a continuous quench-flow system: application to disinfection and pharmaceutical oxidation. Water Res 40(9): 1884-1894

43. Martins RC, Lopes RJG, Quinta-Ferreira RM (2010) Lumped kinetic models for single ozonation of phenolic effluents. Chem Eng J 165(2):678-685

44. Nieto LM, Hodaifa G, Rodríguez S, Giménez JA, Ochando J (2011) Degradation of organic matter in olive-oil mill wastewater through homogeneous Fenton-like reaction. Chem Eng J 173(2):503-510

45. Dantas TLP, Mendonça VP, José HJ, Rodrigues AE, Moreira RFPM (2006) Treatment of textile wastewater by heterogeneous Fenton process using a new composite $\mathrm{Fe} 2 \mathrm{O} 3 /$ carbon. Chem Eng J 118(1-2):77-82

46. Idrissi M, Miyah Y, Benjelloun Y, Chaouch M (2016) Degradation of crystal violet by heterogeneous Fenton-like reaction using Fe/ Clay catalyst with $\mathrm{H}_{2} \mathrm{O}_{2}$. J Mater Environ Sci 7(1):50-58

47. Lázaro Martínez JM, Leal Denis MF, Piehl LL, de Celis ER, Buldain GY, Dall' Orto VC (2008) Studies on the activation of hydrogen peroxide for color removal in the presence of a new $\mathrm{Cu}$ (II)-polyampholyte heterogeneous catalyst. Appl Catal B Environ 82(3-4):273-283

48. Umar Ibrahim Gaya (2014) Heterogeneous photocatalysis using inorganic semiconductor solids. Springer, Dordrecht 
49. Mitsika EE, Christophoridis C, Fytianos K (2013) Fenton and Fenton-like oxidation of pesticide acetamiprid in water samples: kinetic study of the degradation and optimization using response surface methodology. Chemosphere 93(9):1818-1825

50. Sun J-HH, Sun S-PP, Fan M-HH, Guo H-QQ, Qiao L-PP, Sun R-XX (2007) A kinetic study on the degradation of p-nitroaniline by Fenton oxidation process. J Hazard Mater 148(1-2):172-177

51. Karthikeyan S, Gupta VK, Boopathy R, Titus A, Sekaran G (2012) A new approach for the degradation of high concentration of aromatic amine by heterocatalytic Fenton oxidation: Kinetic and spectroscopic studies. J Mol Liq 173:153-163

52. Hou B, Han H, Jia S, Zhuang H, Xu P, Wang D (2015) Heterogeneous electro-Fenton oxidation of catechol catalyzed by nanoFe3O4: kinetics with the Fermi's equation. J Taiwan Inst Chem Eng 56:138-157

53. Badawy MI, Ghaly MY, Gad-Allah TA (2006) Advanced oxidation processes for the removal of organophosphorus pesticides from wastewater. Desalination 194(1-3):166-175

54. Blanco M, Martinez A, Marcaide A, Aranzabe E, Aranzabe A (2014) Heterogeneous Fenton catalyst for the efficient removal of azo dyes in water. Am J Anal Chem 5(8):490-499

55. Farnetti E, Di Monte R, Kašpar J (1999) Inorganic and bio-inorganic chemistry, vol II. EOLSS Publications, Italy

56. Cole-Hamilton DJ (2003) Homogeneous catalysis-new approaches to catalyst separation, recovery, and recycling. Science 299(5613):1702-1706

57. Gaigneaux JPAE, De Vos DE (2002) Scientific bases for the preparation of heterogeneous catalysts. Elsevier, Amsterdam

58. Kosmulski M (2009) Compilation of PZC and IEP of sparingly soluble metal oxides and hydroxides from literature. Adv Colloid Interface Sci 152(1-2):14-25

59. Richards R (2006) Surface and nanomolecular catalysis. Group Tay, Boca Raton

60. Shen J, Li Z, Wu Y, Zhang B, Li F (2015) Dendrimer-based preparation of mesoporous alumina nanofibers by electrospinning and their application in dye adsorption. Chem Eng J 264:48-55

61. Khosla E, Kaur S, Dave PN (2013) Mechanistic study of adsorption of acid orange-7 over aluminum oxide nanoparticles. J Eng 2013:1-8

62. El Boujaady H, Mourabet M, Bennani-Ziatni M, Taitai A (2014) Adsorption/desorption of direct yellow 28 on apatitic phosphate: mechanism, kinetic and thermodynamic studies. J Assoc Arab Univ Basic Appl Sci 16:64-73

63. He J, Yang X, Men B, Bi Z, Pu Y, Wang D (2014) Heterogeneous Fenton oxidation of catechol and 4-chlorocatechol catalyzed by nano-Fe3O4: role of the interface. Chem Eng J 258:433-441

64. Franco CA, Nassar NN, Cortés FB (2014) Removal of oil from oil-in-saltwater emulsions by adsorption onto nano-alumina functionalized with petroleum vacuum residue. J Colloid Interface Sci 433:58-67

65. Naiya TK, Bhattacharya AK, Das SK (2009) Adsorption of Cd(II) and $\mathrm{Pb}(\mathrm{II})$ from aqueous solutions on activated alumina. J Colloid Interface Sci 333(1):14-26

66. Gupta VK, Gupta B, Rastogi A, Agarwal S, Nayak A (2011) A comparative investigation on adsorption performances of mesoporous activated carbon prepared from waste rubber tire and activated carbon for a hazardous azo dye-Acid Blue 113. J Hazard Mater 186(1):891-901

67. Hameed BH, Ahmad AA, Aziz N (2007) Isotherms, kinetics and thermodynamics of acid dye adsorption on activated palm ash. Chem Eng J 133(1-3):195-203

68. Nollet H, Roels M, Lutgen P, Van Der Meeren P, Verstraete W (2003) Removal of PCBs from wastewater using fly ash. Chemosphere 53(6):655-665

69. Hu Z, Zhang D, Wang J (2011) Direct synthesis of amine-functionalized mesoporous silica for $\mathrm{CO}_{2}$ adsorption. Chin J Chem Eng 19(3):386-390

70. Oréfice R, Vasconcelos W (1997) Sol-Gel transition and structural evolution on multicomponent gels derived from the alumina-silica system. J Sol Gel Sci Technol 9(3):239-249

71. Socrates G (2001) Infrared and Raman characteristic group frequencies: tables and charts, 3rd edn. Wiley, New York

72. Centi G, Perathoner S, Biglino D, Giamello E (1995) Adsorption and reactivity of no on copper-on-alumina catalysts. (I) formation of nitrate species and their influence on reactivity in $\mathrm{NO}$ and $\mathrm{NH}_{3}$ conversion. J Catal 152(1):75-92

Publisher's Note Springer Nature remains neutral with regard to jurisdictional claims in published maps and institutional affiliations.

\section{Affiliations}

\section{Laura Covinich $^{1} \cdot$ Fernando Felissia $^{1} \cdot$ Paola Massa $^{2} \cdot$ Rosa Fenoglio $^{2} \cdot$ María C. Area $^{1}$}

Laura Covinich

lgcovinich@gmail.com

1 Programa de Celulosa Y Papel, Instituto de Materiales de Misiones, IMAM (UNaM-CONICET), Félix de Azara 1552, Posadas, Argentina
2 Dpto. de Ingeniería Química/Div. Catalizadores Y Superficies, INTEMA (CONICET-UNMdP), Juan B. Justo 4302, Mar Del Plata, Argentina 